\title{
AS IDEIAS DE DURKHEIM NOS MANUAIS DE HISTÓRIA DA EDUCAÇÃO: CIENTIFICIDADE E MORALIDADE LAICA NA VIDA SOCIAL E NA ESCOLA
}

\author{
Katiene Nogueira da Silva ${ }^{1}$ \\ Giseli Cristina do Vale Gatti ${ }^{2}$
}

\section{RESUMO}

Análise das ideias de Durkheim contidas em manuais de História da Educação, com autores estrangeiros, publicados no Brasil entre 1939 e 2010. Partiu-se de Fernandes (1994), Pickering (2008) e Weiss (2009). Percebeu-se que alguns manuais, apesar de não terem mencionado Durkheim diretamente, abordaram ideias próximas de seu pensamento. Os demais, que foram maioria, mencionaram Durkheim em intensidades diferentes. Neles, Durkheim foi tomado simultaneamente como fonte de informações e de análises, mas, também como portador de uma perspectiva original e influente de educação, a pedagogia sociológica. Além disso, foi possível perceber a existência de críticas a seu pensamento, provenientes, sobretudo, dos autores de manuais vinculados ao campo católico.

Palavras-chave: História, Educação, Formação, Disciplina, Manual, Ensino, Durkheim.

${ }^{1}$ Universidade de São Paulo (USP), São Paulo/SP, Brasil.

${ }^{2}$ Universidade de Uberaba (Uniube), Uberaba/MG, Brasil. 


\section{LAS IDEAS DE DURKHEIM EN LOS MANUALES DE HISTORIA DE LA EDUCACIÓN: CIENTIFICIDAD Y MORALIDAD LAICA EN LA VIDA SOCIAL Y EN LA ESCUELA}

\section{RESUMEN}

Análisis de las ideas de Durkheim contenidas en manuales de Historia de la Educación, con autores extranjeros, publicados en Brasil entre 1939 y 2010. Se partió de Fernandes (1994), Pickering (2008) y Weiss (2009). Se percibió que algunos manuales, a pesar de no haber mencionado a Durkheim directamente, abordaron ideas próximas a su pensamiento. Los demás, que fueron la mayoría, mencionaron a Durkheim en intensidades diferentes. En ellos, Durkheim fue tomado simultáneamente como fuente de informaciones y de análisis, pero, también como portador de una perspectiva original e influyente de educación, la pedagogía sociológica. Además de esto, fue posible percibir la existencia de críticas a su pensamiento, provenientes, sobretodo, de los autores de manuales vinculados al campo católico.

Palabras-clave: Historia, Educación, Formación, Disciplina, Manual, Enseñanza, Durkheim.

\section{THE IDEAS OF DURKHEIM IN THE MANUALS OF HISTORY OF EDUCATION: SCIENTIFIC METHOD AND LAY MORALITY IN SOCIAL LIFE AND IN THE SCHOOL}

\section{ABSTRACT found, coming above all from the authors of manuals linked to the field of Catholicism. \\ LES IDÉES DE DURKHEIM DANS LES MANUELS D'HISTOIRE DE L'ÉDUCATION: SCIENTIFICITÉ ET MORALITÉ LAÏQUE DANS LA VIE SOCIALE ET À L'ÉCOLE}

Analysis of the ideas of Durkheim contained in manuals of the History of Education, from foreign authors published in Brazil from 1939 to 2010. This study was based on Fernandes (1994), Pickering (2008), and Weiss (2009). Some manuals were found not to mention Durkheim directly, but addressed ideas near to his thought. Most of the others mentioned Durkheim, though in different intensities. In them, Durkheim was taken simultaneously as a source of information and analyses, but also as the bearer of an original and influential perspective on education, sociological pedagogy. In addition, critiques of his thought were

Keywords: History, Education, Teacher training, Discipline, Manual, Teaching, Durkheim.

\section{RESUMÉ}

Une analyse des idées de Durkheim contenues dans les manuels d'histoire de l'éducation avec des auteurs étrangers publiés au Brésil entre 1939 et 2010. Elle était basée sur Fernandes (1994), Pickering (2008) et Weiss (2009). Il a été remarqué que certains manuels, bien qu'ils ne mentionnent pas directement Durkheim, abordaient des idées proches de sa pensée. Les autres, 
qui étaient majoritaires, ont mentionné Durkheim à différentes intensités. Durkheim y était pris à la fois comme source d'information et d'analyse, mais aussi comme porteur d'une perspective originale et influente de l'éducation, de la pédagogie sociologique. De plus, il était possible de percevoir l'existence de critiques à sa pensée, émanant principalement des auteurs de manuels liés au domaine catholique.

Mots-clés: Histoire, Éducation, Formation, Discipline, Manuel, Enseignement, Durkheim. 


\section{INTRODUÇÃO}

Quando chegou a minha vez, relatei constrangido o que fazia. Ao mencionar Durkheim [...] esclareci: 'leio no bonde'. Foi um escândalo. [...] Se ele tivesse perguntado, explicaria que lia em uma viagem que começava na Praça da Sé e terminava na Penha, em horas que permitiam grande sossego no bonde... Existiam outros tipos de rusticidade e de tortura dos refinamentos da alta cultura. Inclusive havia um patamar de ignorância que brigava com o padrão sofisticado e complexo de aprendizagem. [Explicação de Florestan Fernandes para seu professor Arbousse Bastide de como lia Durkheim].(Citado em Fétizon, 1986, p. 472-473)

A temática deste artigo refere-se à História Disciplinar da História da Educação, cujo objeto são as ideias de Durkheim contidas em manuais de História da Educação com autores de diferentes países, excetuando o Brasil, que foram traduzidos para o português entre 1939 e 2010. Partiu-se da leitura cuidadosa de interpretações correntes sobre o pensamento de Durkheim, em especial, Fernandes (1994), Pickering (2008) e Weiss (2009), mas, também, dos escritos educacionais do próprio Durkheim, destacadamente, Educação Moral (2012) e A Evolução Pedagógica (1995). A apresentação dos resultados está dividida em duas partes. Na primeira, estão apresentadas as ideais sobre sociedade e educação de Durkheim. Na segunda, estão apresentados os resultados daquilo que foi possível levantar sobre Durkheim nos manuais de História da Educação. Por fim, nas Considerações Finais, consta a análise dos principais contornos do conteúdo disposto sobre Durkheim nos manuais de História da Educação.

\section{SOBRE AS IDEIAS DE DURKHEIM.}

As ideias e a atuação acadêmica de Durkheim (1858-1917) são distintivas de um pensamento e de uma ação que deixou marcas importantes no pensamento social e educacional, com repercussões visíveis na pesquisa, nos 
estudos e nas ações sociais. Weiss (2009, p. 170) argumenta que "é em seus escritos sobre a educação que encontramos a maior parte de suas proposições normativas, que assumem a forma de uma pedagogia”. Nessa direção, Pickering (2008, p.202) alerta para o fato que os escritos sobre educação de Durkheim não foram publicados nos L'Année Sociologique, importante periódico relacionado a implantação da Sociologia, sendo que estes escritos educacionais apareceram postumamente, com destaque para a publicação da obra L'Évolution pédagogique en France, o que ocorreu apenas em 1938, cuja disseminação mais larga ocorreria apenas após o final da Segunda Guerra Mundial.

Segundo Pickering (2008, p. 202), quase todos os escritos sobre educação de Durkheim foram realizados em um momento importante do processo de consolidação da Terceira República na França (1870-1940), quando o treinamento de professores foi tomado à sério, com Durkheim tendo papel importante como conferencista e, depois, como responsável por cursos de formação de professores no âmbito pedagógico.

Este percurso diferenciado da produção de Durkheim no âmbito sociológico e no âmbito educacional parece ter favorecido intepretações sobre sua obra que não conseguiram perceber conexões entre ambas. Porém, mais recentemente, abordagens do conjunto destes escritos têm favorecido análise mais abrangente e completa.

Segundo Weiss (2009, p. 169), em seus escritos sobre Educação, Durkheim opera uma distinção importante entre Ciências da Educação e Pedagogia. As Ciências da Educação tomam os fatos sociais como coisas, portanto, passíveis de análise pelo método científico, possuindo uma dimensão explicativa, que pode ser sintetizada em duas formulações: "O que a educação foi” e "O que a educação é”. A Pedagogia, por seu turno, seria uma reflexão metódica e documentada sobre a prática de ensino, possuindo uma dimensão propositiva, que poderia ser resumida na expressão: “O que deveria ser a Educação". 
Para a autora, Durkheim parte da ideia de que a Ciência pode enunciar juízos de fato sobre qualquer coisa e mesmo sobre valores, emergindo daí seu objetivo de criação de uma Ciência da Moral, na qual parte-se da observação do que é moral em uma sociedade em um determinado período para definir a moralidade a partir dos fatos (Weiss, 2009, p. 171). Se para Durkheim a educação deve ser tomada simultaneamente como fato e processo social, o objetivo primeiro da educação seria a manutenção e a preservação da sociedade:

A educação é a ação exercida pelas gerações adultas, sobre as gerações que não se encontram ainda preparadas para a vida social; tem por objeto suscitar e desenvolver, na criança, certo número de estados físicos, intelectuais e morais, reclamados pela sociedade política, no seu conjunto, e pelo meio especial a que a criança, particularmente, se destine (1978, p. 32).

A Ciência da Educação seria o estudo exaustivo dos sistemas educativos, no passado e em sua situação atual, com a percepção de que o fenômeno educativo guarda relação com todas as dimensões da vida social. Todavia, o conhecimento do passado e da situação atual da educação na França não se coloca para Durkheim como mera constatação, mas, como construção de um alicerce para a proposição de mudanças, que não sejam fruto de vontades irrefletidas. A reflexão pedagógica partiria então dos achados da Ciência da Educação para poder estruturar suas proposições reformistas no campo educacional.

Durkheim estava comprometido com ideias da Terceira República, nas quais se almejava formar o cidadão e institucionalizar o regime republicano, por meio da proposição de uma educação laica, destinada à formação do caráter moral do cidadão moderno, o que, segundo Weiss (2009, p. 177), foi efetivado por Durkheim com base "em seu diagnóstico acerca da organização social, dos ideais sociais e de seu descompasso com a educação e a moral vigentes". $\mathrm{Na}$ época, era fundamental enfrentar o problema de ensinar a moral laica em contraponto com os princípios das religiões reveladas, pois, seria "uma 
educação que abdica de qualquer referência aos princípios sobre os quais repousam as religiões reveladas, que se apoia exclusivamente sobre ideias, sentimentos e práticas que se justificam unicamente pela razão, em uma palavra, uma educação puramente racionalista” (Durkheim, 2012, p. 19).

Durkheim precisou então trabalhar no caminho da descoberta de quais seriam os equivalentes racionais dessas noções religiosas, com a clareza de que que as marcas de uma moral laica estariam no espírito de autonomia e no caráter racionalista. Nessa direção, destaca-se o espírito de disciplina, que nos leva a reconhecer as limitações que nos cercam e a desenvolver o autocontrole, pois é por meio da disciplina que se aprende a moderação do desejo, sem a qual o homem não poderia ser feliz. Graças à autoridade de que são revestidas, as regras morais têm força para barrar os desejos, as necessidades e os apetites quando eles se tornarem imoderados. Mediante a disciplina seria possível ensinar a criança a moderar os seus desejos, limitar os seus apetites e definir os objetivos de sua atividade; essa limitação seria condição para a sua felicidade e para a sua "saúde" moral.

Deste modo, a disciplina moral tem papel fundamental na formação do caráter e da personalidade. O autocontrole seria então como uma maestria de si que é forjada pela disciplina moral. A propósito disso, Fernandes (1994) apresenta a seguinte reflexão:

\footnotetext{
Mas, quanto à subjetividade, não seria a disciplina uma violentação, uma diminuição do ser, uma mera polícia exterior e material cuja única utilidade seria a de impedir que certos atos sejam cometidos? Limitando e refreando os desejos, impedindo que se desenvolvam sem limites, não violentaria a constituição natural do homem, entravando seu livre desenvolvimento? (p. 84).
}

Porém, há uma ideia de Durkheim que muitas vezes é negligenciada pelos analistas, a de que as regras não devem ser tomadas como ídolos, sendo necessário “erguer os olhos”, pois que, para ele, a existência de sujeitos anômicos é importante para a renovação social, em seu esforço de contestar a 
moral em busca do novo, mas, não como pura contestação, o que seria pouco construtivo (WEISS, 2009, p. 181).

Há, no entanto, uma hierarquia a ser respeitada, relacionada aos fins da Humanidade, de caráter abstrato, e aos fins da Pátria e da Família, de caráter concreto. Assim, dado que o alcance planetário das regras sociais é difícil, o mais próximo, são as sociedades constituídas na forma de nações. Portanto, Durkheim centraliza na Pátria e no Estado Nacional, os fins da Humanidade. Para ele, o Estado deveria contemplar mais justiça, por meio de uma moralidade mais elevada, organizando-se para que exista uma relação mais exata dos méritos dos cidadãos com sua condição, bem como para que os padecimentos dos indivíduos possam ser diminuídos ou mesmo prevenidos (WEISS, 2009, p.183). Assim, a escola teria como objetivo central vincular as crianças à Pátria, na qual as ideias de Humanidade estariam presentes, pois a escola é o único veículo no qual a criança pode conhecer a pátria e a amá-la de modo organizado, o que confere importância primordial ao papel da escola na formação moral do país (WEISS, 2009, p. 183).

Nessa direção, Fernandes (1994, p. 99) assevera que se antes, sob a moral religiosa, as condutas eram controladas pelo temor e pelo amor a Deus, diante de uma moral laica qual seria o freio que conteria as paixões? Em uma “escola sem Deus”, a moralidade passou a se fundar na construção do espírito da disciplina e do amor à pátria, sendo preciso ligar as crianças à pátria, fazendo-as amar um ideal social ao qual pudessem dedicar sua devoção e sacrifício. Para a autora:

Na sociedade moderna, a fome poderia ser saciada graças à vinculação dos indivíduos a três grupos sociais que Durkheim seleciona como objetos do desejo: família, pátria, humanidade. Mas os objetos são hierarquizados de modo a privilegiar um deles: a pátria. [...] Por outro lado, à medida que a sociedade progride e se centraliza, a vida familiar adquire importância menor enquanto a vida do grupo político (vida comum a todos os seus membros) é a que atrai o indivíduo ligando seu desejo a outros objetos. Como o centro da gravidade da vida moral deslocou-se para um novo objeto, a família tornou-se um órgão secundário do Estado (FERNANDES, 1994, p. 95). 
Neste registro, que se mostrou bastante potente em diferentes sociedades ao longo do Século XX, a formação da criança está relacionada ao desenvolvimento inicialmente do espírito de disciplina, que se trata de um dever. Para além da disciplina, também deve ser desenvolvido na criança o espírito de adesão à sociedade, visto como um bem, mas, que comporta forças conservadoras e inventivas. Por fim, a criança deve desenvolver espírito de autonomia, que é circunscrito ao desejo do possível.

\title{
2. DURKHEIM NOS MANUAIS DE HISTÓRIA DA EDUCAÇÃO: DIFERENTES APROPRIAÇÕES
}

A partir do exame dos manuais de História da Educação foi possível perceber as diferentes formas como os autores apresentaram elementos da obra de Durkheim em seus textos. Para analisar estas diferentes abordagens, trabalhamos com o conceito de apropriação de Chartier (1991), que nos permite compreender como um autor e sua obra podem ser interpretados e reinventados a partir da leitura e da escrita de outros:

\begin{abstract}
A apropriação, a nosso ver, visa uma história social dos usos e das interpretações, referidas a suas determinações fundamentais e inscritas nas práticas específicas que as produzem. Assim, voltar a atenção para as condições e os processos que, muito concretamente, sustentam as operações de produção do sentido (na relação de leitura, mas em tantos outros também) é reconhecer, contra a antiga história intelectual, que nem as inteligências nem as idéias são desencarnadas, e, contra os pensamentos do universal, que as categorias dadas como invariantes, sejam elas filosóficas ou fenomenológicas, devem ser construídas na descontinuidade das trajetórias históricas (CHARTIER, 1991, p. 180).
\end{abstract}

Buscou-se analisar os manuais de História da Educação a partir desta perspectiva. A escolha de manejar o conceito de apropriação para compreender como determinado autor é referenciado, compreendido, citado, já foi feita em 
outros trabalhos e é importante mencionar o artigo publicado por Catani, Catani e Pereira (2001) sobre as apropriações da obra de Pierre Bourdieu no campo educacional brasileiro. No quadro abaixo reunimos as informações relativas ao trabalho de localização das referências à Durkheim nos livros examinados.

Quadro 1 - Menções às ideias educativas de Durkheim nos manuais de História da Educação traduzidos para o português e publicados no Brasil entre 1939 e 2010.

\begin{tabular}{|c|c|c|c|c|c|c|}
\hline $\begin{array}{c}\text { AUTOR(ES)- } \\
\text { ORGANIZADORES } \\
\text { /ANO 1 a EDIÇÃO } \\
\text { EM PORTUGUÊS }\end{array}$ & $\begin{array}{l}\text { EDIÇÃO } \\
\text { ANALISADA } \\
\text { /ANO }\end{array}$ & $\begin{array}{c}\text { PÁGINAS } \\
\text { SOBRE } \\
\text { DURKHEIM }\end{array}$ & $\begin{array}{c}\text { N. } \\
\text { PÁGS. }\end{array}$ & $\begin{array}{l}\text { PÁGS. } \\
\text { DA } \\
\text { OBRA }\end{array}$ & $\%$ & $\begin{array}{c}\text { TÍTULOS E } \\
\text { SUBTÍTULOS } \\
\text { SOBRE DURKHEIM }\end{array}$ \\
\hline $\begin{array}{c}\text { Monroe } \\
1939\end{array}$ & $\begin{array}{l}2^{\mathrm{a}} \cdot \mathrm{ed} . \\
1946\end{array}$ & - & OO & 463 & 00,0 & $\begin{array}{c}\text { Nenhum. } \\
\text { Observação: Há } \\
\text { conteúdos que se } \\
\text { aproximam de } \\
\text { Durkheim: sobre a } \\
\text { tendência psicológica } \\
\text { na educação } \\
\text { (Pestalozzi, Herbart, } \\
\text { Froebel); sobre a } \\
\text { tendência científica } \\
\text { moderna (Spencer e } \\
\text { Huxley); sobre a } \\
\text { tendência sociológica } \\
\text { na educação (Comte); } \\
\text { sobre a tendência } \\
\text { eclética do início do } \\
\text { Século XX } \\
\text { (Psicologia, Ciência e } \\
\text { Sociologia). }\end{array}$ \\
\hline $\begin{array}{c}\text { Riboulet } \\
1951 \\
\text { (4v.) }\end{array}$ & $\begin{array}{c}1^{\mathrm{a}} . \mathrm{ed} . \\
1951 \\
(4 \mathrm{v} .)\end{array}$ & - & OO & 858 & 00,0 & $\begin{array}{c}\text { Nenhum. } \\
\text { Observação: Há } \\
\text { conteúdos que se } \\
\text { aproximam de } \\
\text { Durkheim, sobre os } \\
\text { efeitos da Revolução } \\
\text { Francesa na } \\
\text { Educação, sobre a } \\
\text { Pedagogia } \\
\text { Protestante e sobre o } \\
\text { positivismo francês } \\
\text { (Comte) e o } \\
\text { evolucionismo inglês } \\
\text { (Spencer). }\end{array}$ \\
\hline $\begin{array}{r}\text { Gal } \\
1954\end{array}$ & $\begin{array}{l}1^{\mathrm{a}} . \mathrm{ed} . \\
1954\end{array}$ & - & OO & 151 & 00,0 & $\begin{array}{c}\text { Nenhum. } \\
\text { Observação: Há } \\
\text { conteúdos que se } \\
\text { aproximam da época } \\
\text { na qual Durkheim } \\
\text { produz suas reflexões } \\
\text { sobre educação, }\end{array}$ \\
\hline
\end{tabular}




\begin{tabular}{|c|c|c|c|c|c|c|}
\hline & & & & & & $\begin{array}{c}\text { incluindo: A } \\
\text { Revolução } \\
\text { Pedagógica; A } \\
\text { Educação na França e } \\
\text { no Estrangeiro nos } \\
\text { Séculos XIX e XX; As } \\
\text { Novas Tendências. }\end{array}$ \\
\hline $\begin{array}{c}\text { Luzuriaga } \\
1955\end{array}$ & $\begin{array}{c}2^{\mathrm{a}} . \text { ed. } \\
\text { (revista) } \\
1963\end{array}$ & $\begin{array}{c}10 \\
253 \\
255^{-256}\end{array}$ & 04 & 281 & 01,4 & $\begin{array}{l}\text { Cap. } 1 \text { - História da } \\
\text { Educação e da } \\
\text { Pedagogia - Item } 5 \text { - } \\
\text { Valor dêstes estudos } \\
\text { (p.10); Cap. 10 - A } \\
\text { pedagogia } \\
\text { contemporânea - } \\
\text { Item } 4 \text { - A pedagogia } \\
\text { social (p.253 e p.255- } \\
\text { 256). Observação: } \\
\text { Além disso, houve } \\
\text { menção direta a } \\
\text { pedagogia positivista } \\
\text { (Comte e Spencer) e } \\
\text { ao cientificismo } \\
\text { (Huxley). }\end{array}$ \\
\hline $\begin{array}{c}\text { Hubert } \\
1957\end{array}$ & $\begin{array}{c}1^{\mathrm{a}} \cdot \mathrm{ed} . \\
1957\end{array}$ & $\begin{array}{c}319-327 \\
382-383 \\
399\end{array}$ & 12 & 406 & 02,9 & $\begin{array}{l}\text { Segunda parte - As } \\
\text { Doutrinas } \\
\text { Pedagógicas - Cap. } \\
\text { IV - Algumas } \\
\text { tendências da } \\
\text { Pedagogia } \\
\text { Contemporânea - } \\
\text { Item 1 - Émile } \\
\text { Durkheim (p.319- } \\
\text { 327); Conclusão } \\
\text { (p.382-383); } \\
\text { Bibliografia Sumária } \\
\text { - Sôbre Durkheim (p. } \\
\text { 399). }\end{array}$ \\
\hline $\begin{array}{l}\text { Eby } \\
1962\end{array}$ & $\begin{array}{c}2^{\mathrm{a}} \text { impr. } \\
1970\end{array}$ & - & OO & 633 & OO & $\begin{array}{c}\text { Nenhum. } \\
\text { Observação: Há } \\
\text { conteúdos de temas } \\
\text { importantes da época } \\
\text { de Durkheim, a } \\
\text { saber: os sistemas } \\
\text { nacionais de } \\
\text { educação; a escola } \\
\text { secundária na } \\
\text { Alemanha; as } \\
\text { mudanças } \\
\text { educacionais da } \\
\text { Terceira República } \\
\text { francesa; os limites } \\
\text { do ensino } \\
\text { humanístico; o } \\
\text { impacto da biologia; } \\
\text { o evolucionismo } \\
\text { pedagógico; a ênfase } \\
\text { dada ao ensino de }\end{array}$ \\
\hline
\end{tabular}




\begin{tabular}{|c|c|c|c|c|c|c|}
\hline & & & & & & $\begin{array}{l}\text { ciências; a ciência } \\
\text { como único método } \\
\text { para a verdade; a } \\
\text { necessidade de } \\
\text { instituir currículos } \\
\text { realistas. }\end{array}$ \\
\hline $\begin{array}{c}\text { Ponce } \\
1963\end{array}$ & $\begin{array}{l}21^{\mathrm{a}} \mathrm{ed} . \\
2005\end{array}$ & $\begin{array}{c}20-21 \\
28 \\
149\end{array}$ & 04 & 198 & 2,02 & $\begin{array}{c}\text { Capítulo I - A } \\
\text { educação na } \\
\text { comunidade } \\
\text { primitiva; Capítulo } \\
\text { VI - A educação do } \\
\text { homem burguês - } \\
\text { Segunda parte: Da } \\
\text { Revolução Francesa } \\
\text { ao século XIX }\end{array}$ \\
\hline $\begin{array}{c}\text { Larroyo } \\
1970\end{array}$ & $\begin{array}{l}1^{\mathrm{a}} \mathrm{ed} . \\
1970 \\
(2 \mathrm{v} .)\end{array}$ & $\begin{array}{c}841 \\
846-847\end{array}$ & 03 & 1000 & 0,3 & $\begin{array}{c}\text { Capítulo VI - } \\
\text { Pedagogia Social - } 3 . \\
\text { Pedagogia } \\
\text { Sociológica (P. Barth, } \\
\text { E. Durkheim, K. } \\
\text { Weiss, C. Peters, W. } \\
\text { Waller, G. S. Counts) }\end{array}$ \\
\hline $\begin{array}{c}\text { Debesse \& Mialeret } \\
\text { (Org.) } \\
1974-7 \\
\text { (3v.) }\end{array}$ & $\begin{array}{l}1^{\mathrm{a}} \mathrm{ed} . \\
1974-7 \\
(3 \mathrm{v} .)\end{array}$ & $\begin{array}{c}96 \\
128-130 \\
192 \\
203 \\
213 \\
226-227 \\
250 \\
257 \\
266-267 \\
382 \\
415\end{array}$ & 15 & 559 & 2,68 & $\begin{array}{c}\text { Cap. } 2 \text { - A Idade } \\
\text { Média - A. Antes de } \\
\text { Carlos Magno - 1. Os } \\
\text { começos. O período } \\
\text { feudal - 2. A } \\
\text { formação dos } \\
\text { clérigos; Cap. 3 - A } \\
\text { Renascença - } \\
\text { Abundância das } \\
\text { publicações e dos } \\
\text { estabelecimentos de } \\
\text { ensino, A Reforma e } \\
\text { a Contra-Reforma, A } \\
\text { criação dos Colégios } \\
\text { de Jesuítas, A } \\
\text { pedagogia erásmica, } \\
\text { O ideal pedagógico } \\
\text { de Rabelais, O } \\
\text { pensamento } \\
\text { pedagógico de Michel } \\
\text { de Montaigne (1533- } \\
\text { 1592), Bibliografia; } \\
\text { Cap. 5 - Da } \\
\text { Revolução Francesa } \\
\text { aos começos da } \\
\text { Terceira República, } \\
\text { Bibliografia; Cap. 6 - } \\
\text { A época } \\
\text { contemporânea, } \\
\text { Bibliografia. }\end{array}$ \\
\hline Manacorda & $1^{\mathrm{a}}$ ed. & 272 & 01 & 382 & 0,26 & $\begin{array}{l}\text { A Educação no } \\
\text { Oitocentos - 2. A }\end{array}$ \\
\hline
\end{tabular}


Revista História da Educação (Online), 2019, v. 23: e93211

e-ISSN: 2236-3459 http://seer.ufrgs.br/asphe

\begin{tabular}{|c|c|c|c|c|c|c|}
\hline 1989 & 1989 & & & & & utopia socialista \\
\hline $\begin{array}{l}\text { Cambi } \\
1999\end{array}$ & $\begin{array}{l}1^{\mathrm{a}} \mathrm{ed} . \\
1999\end{array}$ & $\begin{array}{c}384 \\
410 \\
468-470 \\
499 \\
584\end{array}$ & 07 & 701 & 0,99 & $\begin{array}{c}\text { Quarta Parte - A } \\
\text { época } \\
\text { contemporânea - I. } \\
\text { Características da } \\
\text { educação } \\
\text { contemporânea - 2. } \\
\text { Educação e ideologia; } \\
\text { II. O século XIX: o } \\
\text { século da pedagogia. } \\
\text { Conflitos ideológicos, } \\
\text { modelos formativos, } \\
\text { saberes da educação } \\
\text { - 1. Burguesia e } \\
\text { povo: entre } \\
\text { ideologias } \\
\text { pedagógicas e } \\
\text { conflitos educativos, } \\
\text { 6. Sociedade } \\
\text { industrial e } \\
\text { educação: entre } \\
\text { positivismo e } \\
\text { socialismo, 9. O } \\
\text { nascimento da } \\
\text { pedagogia científica e } \\
\text { experimental; III - O } \\
\text { século XX até os anos } \\
\text { 50. "Escolas Novas” e } \\
\text { ideologias da } \\
\text { educação - 8. O } \\
\text { crescimento } \\
\text { científico da } \\
\text { pedagogia. }\end{array}$ \\
\hline $\begin{array}{l}\text { Gauthier; Tardif, } \\
\text { (Org). } \\
2010\end{array}$ & 2010 & $\begin{array}{c}43 \\
60-63 \\
66 \\
68 \\
70 \\
72-75 \\
87 \\
92 \\
110 \\
112 \\
114-119 \\
123-124 \\
148\end{array}$ & 26 & 527 & 4,90 & $\begin{array}{c}\text { Cap. 1 - Os gregos } \\
\text { antigos e a fundação } \\
\text { da tradição educativa } \\
\text { ocidental; Cap. } 2 \text { - O } \\
\text { Nascimento da } \\
\text { Escola na Idade } \\
\text { Média; Cap. } 3 \text { - O } \\
\text { Renascimento e a } \\
\text { Educação } \\
\text { Humanista; Cap. 4 - } \\
\text { O século XVII e o } \\
\text { problema do método } \\
\text { no ensino ou o } \\
\text { nascimento da } \\
\text { Pedagogia; Cap. } 5 \text { - } \\
\text { Jean-Jacques } \\
\text { Rousseau: o } \\
\text { Copérnico da } \\
\text { Pedagogia }\end{array}$ \\
\hline
\end{tabular}




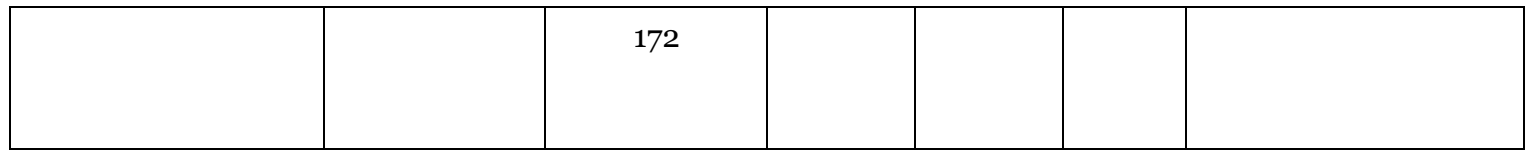

Fonte: elaborado pelas autoras

\subsection{MANUAIS QUE NÃO MENCIONAM DIRETAMENTE DURKHEIM}

No exame destes livros foi possível identificar os modos pelos quais se deram as diferentes apropriações das ideias de Durkheim. Dentre os doze títulos analisados, quatro não fizeram qualquer menção a Durkheim, foram eles: Monroe (1946); Riboulet (1951); Gal (1954); Eby (1970). No entanto, foi possível perceber nestes livros aproximações com a Sociologia da Educação de Durkheim.

\subsubsection{A "HISTÓRIA DA EDUCAÇÃO" DE PAUL MONROE (1869-1947)}

O manual de História da Educação de Paul Monroe teve sua primeira edição em português publicada em 1939, pela Companhia Editora Nacional3. Trata-se de uma tradução realizada por Nelson Cunha de Azevedo, a partir do original em inglês intitulado A Brief Course in the History of Education, publicado originalmente em 1907, pela The Macmillan Company, em Nova Iorque4.

Provavelmente, dado o caráter tardio da publicação das obras sobre

\footnotetext{
${ }^{3}$ Roballo (2011, p.996) afirma que "o manual 'História da Educação' de Monroe atingiu 19 edições, sendo que a primeira edição (1939) foi publicada durante a gestão de Fernando Azevedo [na Coleção Atualidades Pedagógicas], e as demais (re)edições tornaram-se parte da coleção permanente - padrão azevediano - publicadas durante a gestão do segundo diretor da coleção, Damasco Penna: 1946, 1952, 1953, 1956, 1958, 1968, 1969, 1970, 1972, 1974, 1976, 1977, 1978, 1979, 1983, 1984, 1985 e 1987; tendo larga tiragem de aproximadamente 90.000 exemplares".

4 Cópia digital disponível em: https://archive.org/details/abriefcourseinho3monrgoog/page/n5. Acesso em 18 mar. 2019.
} 
educação de Durkheim (Pickering, 2008, p.202), não foram constatadas referências diretas à Durkheim no manual de Monroe. Todavia, nos quatro últimos capítulos da obra, o autor discorre sobre temas próximos das reflexões realizadas por Durkheim, a saber: tendência psicológica na educação; tendência científica moderna na educação, tendência sociológica da educação e, a título de conclusão, sobre a tendência eclética do presente (início do Século XX).

Comte, que é uma influência importante para a sociologia de Durkheim, é mencionado por Monroe em duas oportunidades. Deste modo, Monroe percorre um conjunto de ideias que se aproximam da sociologia da educação que anima os escritos sobre educação de Durkheim, conforme podemos examinar a seguir.

Assim, a educação torna-se a mais importante função social. Ela deveria ser controlada pelo estado e não por particulares (Monroe, 1946, p. 424).

os motivos morais passaram a ser mais acentuados do que nunca, motivos morais, porém, de caráter diferente. Assim, como a educação nas mãos dos pais procurava a orientar a criança para o sucesso prático da vida; e a educação da Igreja, orientá-la para a preparação da sua própria salvação eterna, assim a educação do estado procurara controlar a criança para o bem-estar da sociedade, o qual inclui o do indivíduo e o dos seus companheiros. Consequentemente, como forma de controle, a educação é apenas um instrumento da sociedade, semelhante à lei, à fôrça policial, à religião e à Igreja, à opinião pública organizada e aos vários costumes e tradições socais. Mas, como tal, ela atua de um modo peculiar, não diretamente pela fôrça, mas indiretamente por meio do poder sugestivo de idéias e através da instrução; não imediatamente sobre o adulto, mas através da geração vindoura (Monroe, 1946, p. 425).

\subsubsection{A "HISTÓRIA DA PEDAGOGIA" DE LOUIS RIBOULET (1871-1944)}

Em Riboulet também não há referências diretas à Durkheim, com predominância da análise sobre o cienticifismo e o evolucionismo, todavia, em 
um registro combativo, no qual são apontados os erros destas correntes, quando elas rejeitam princípios cristãos na análise do campo educacional. No terceiro volume da obra é possível verificar que Riboulet assinala os avanços educacionais alcançados nos Estados Unidos durante o Século XIX. Ressalta os esforços de Guizot, na França, em torno da preparação dos mestres, com a constituição de escolas normais e de aplicação. Constatou também a estruturação de uma ciência e de uma psicologia da criança, por meio das contribuições de Pestalozzi, Froebel e La Salle. Ponderou sobre a necessidade de limitar a expansão de escolas profissionais e sobre o abuso das ciências em detrimento de conteúdo vinculado às Humanidades. Ressaltou os problemas advindos da Revolução Francesa, pois, para Riboulet:

Os sentimentos cristãos têm diminuído, pouco a pouco, se não desapareceram completamente. Princípios funestos saídos da Revolução têm contribuído a desagregar o laço familiar: secularização do matrimônio, negação de toda relação de dependência da família, idéia de que os meninos pertencem primeiramente ao Estado, etc. (RIBOULET, 1951, v.3, p. 187).

Em seguida, Riboulet desfere críticas as ideias de gratuidade, obrigatoriedade e neutralidade da escola, bem como, sobretudo, da ideia de monopólio do Estado sobre a escola. Sobre a neutralidade, ele afirma que:

A neutralidade escolar é uma das conseqüências das doutrinas de Rousseau, erigidas em decreto pela Revolução. [...] A neutralidade não se pode admitir. É contrária aos direitos da Igreja, cujo filho o cristão se tornou pelo batismo; contrária aos direitos dos pais que deram o filho a Cristo e à Igreja; contrária aos direitos mais sagrados da criança, na qual a escola neutra abafa a mais nobre de todas as vidas, a vida superior e divina (RIBOULET, 1951, v.3, p. 191-192).

Ainda no terceiro volume de sua História da Pedagogia, Riboulet procede a análise sobre Pestalozzi, acusando-o de ser portador de um deísmo vago, carente de conviç̧ões e, por isso, incapaz de dar educação moral e 
religiosa. Para ele, nas principais obras de Pestalozzi, Leonardo e Gertrudes e Como Gertrudes educa os filhos, "não se encontra nem mãe cristã, nem membro da Igreja, nem dogma de fé, nem palavra da Sagrada Escritura. Êle não crê no mistério da Santíssima Trindade; ignora a revelação. Sua fé não é senão espécie de filantropia geral” (RIBOULET, 1951, v.3, p. 211).

No quarto volume, Riboulet, prossegue sua análise das pedagogias protestantes. Ao tratar de William James, salienta a influência de Hegel, bem como procede crítica aguda, ao constatar em James a consideração de que "os atributos de Deus tornam-se os das coisas: Deus não é eterno, não é criador, não é todo-poderoso" (RIBOULET, 1951, v.4, p. 20). Em seguida, prossegue a análise no mesmo tom combativo, com a abordagem das escolas psicológicas, do kantismo e de Fichet.

Adentra as temáticas do positivismo e do evolucionismo. Do primeiro afirma que se trata de um empirismo renovado, com pretensa raiz científica, que estabelece uma finalidade moral para a educação, relacionada ao bem da Humanidade, pelo caminho que vai do coração, à inteligência e a sociabilidade. Para Riboulet, as bases da teoria de Comte são frágeis, o que se aplica também a seu sistema educacional, pois, o "sistema educacional de Comte funda-se muito exclusivamente na matemática e nas ciências. As lêtras que constituem a melhor disciplina intelectual, são excluídas do programa; não entram nêle senão indiretamente. É o triunfo do espírito científico”. Quanto ao evolucionismo, ao abordar Spencer, o autor faz severas críticas. Inicia pelo apontamento de proximidades entre o positivismo francês e o evolucionismo inglês, pois que "admite transformações sucessivas da humanidade, a criação, por meio da imaginação, de mitos religiosos e filosóficos, e faz da experimentação científica, o único critério do conhecimento certo" (RIBOULET, 1951, v.4, p. 71). Nessa direção, Riboulet desfere forte crítica aos evolucionistas:

Os evolucionistas sustentam que as idéias morais se formam pouco a pouco, sob a influência do instinto de conservação, pela hereditariedade, educação e legislação. Essa concepção históricamente 
falsa, destrói a liberdade e a responsabilidade. Enfim, rejeita toda religião revelada, e em seu sistema educacional, não apelam senão vagamente para os princípios religiosos (RIBOULET, 1951, v.4, p. 71).

\subsubsection{A HISTÓRIA DA EDUCAÇÃO DE ROGER GAL (1906-1966)}

O conteúdo da obra de Gal não é muito extenso, com 151 páginas, em livro com formato menor que o usual. Nos três últimos capítulos há conteúdos que guardam relação com o pensamento de Durkheim, mas Gal não faz nenhuma menção em particular do autor, nem mesmo sobre Comte, dado que a obra, quando se refere a este período histórico, aborda as reformas educacionais ocorridas na França e em outros países.

Assim, no capítulo sétimo, "A Revolução Pedagógica”, Gal aborda os predecessores das mudanças radicais ocorridas na esfera educacional, destacadamente, Locke e Rousseau. Notou também as linhas de continuidade em relação a Rousseau nas contribuições de Kant, Basedow e Pestalozzi. Finalizou, com a abordagem das inovações advindas da Revolução Francesa, destacadamente, para as ações empreendidas por Condorcet e Lakanal.

A Educação na França e no estrangeiro nos Séculos XIX e XX é o título do capítulo oitavo, no qual aborda as dificuldades iniciais da França revolucionária no campo educacional, até o advento da Terceira República, que trouxe alterações educacionais significativas, por meio de reformas do ensino primário, promovidas por Jules Ferry e Paul Bert, em 1881 e 1882. Nos anos seguintes, implantam-se a obrigatoriedade, a gratuidade e a neutralidade escolar. Além disso, desenvolve-se, a partir da influência de Froebel, as escolas maternais. Ainda neste capítulo, Gal trata: do desenvolvimento do ensino secundário, no qual emergem os liceus e a separação entre o ensino científico e literário, bem como do ensino feminino; da organização do ensino profissional, tendo como marco a Escola de Práticas Domésticas, em 1892; do Ensino Superior, com o reestabelecimento das universidades, ênfase nas faculdades de 
ciências e a consolidação dos estudos sobre a Psicologia da Criança e da Pedagogia; da situação da educação no estrangeiro, na Inglaterra, nos Estados Unidos e na União Soviética. Finaliza, com apontamentos sobre a educação de adultos, com foco na continuidade de estudos.

No capítulo nono, "As Novas Tendências", Gal discorre sobre os projetos de reforma educativa na França, particularmente, do chamado projeto conhecido como Projeto Langevin-Walon, de 1947. Em seguida, abordou a contribuição da Psicologia para a mudança da forma de ver e tratar a criança, com destaque para o papel desempenhado pelos fundadores Stanley Hall, W. James, Dewey, Ellen Key e para os continuadores, "Pierón, Claparède, Wallon e Piaget, etc." (GAL, 1954, p. 140). Abordou ainda os métodos novos, com ênfase na oposição entre o conteudismo e a ideia que escola é vida, destacando as lições de coisas, como estratégia de ir do concreto ao abstrato, bem como, apresentando o valor cultural do ensino manual e profissional, conforme Kerchensteiner (p. 143), mas, também, ressaltando a importância dos métodos ativos, que tomam a criança como artesã de sua própria educação, recorrendo à Decroly, Montessori e Freinet.

Ainda no capítulo nono, que é o último da História da Educação de Roger Gal, o autor enfatiza: as experiências de individualização do ensino, por meio da apresentação do Plano Dalton e da experiência de Washburne, em Winnetka (p. 145); a fusão entre a individualização e os aspetos coletivos a partir do Instituto Rousseau em Genebra, com ênfase na cooperação social e no espírito de iniciativa; na ideia de disciplina assumida pelo próprio aluno, em uma prática de self-governement. Abordou, também, as ideias de trabalho em grupos (Cousinet), cooperativas escolares (Profit), trabalho livre, pessoal e coletivo e imprensa escolar (Freinet). Assinalou a emergência do escotismo, bem como a constituição da Liga Internacional para a Educação Nova, fundada por A. Ferrière, mediante o apoio de "eminentes sábios ou psicólogos, como Langevin, Walon, Pierón, Piaget, etc.” (GAL, 1954, p. 149). 


\subsubsection{A HISTÓRIA DA EDUCAÇÃO MODERNA DE FREDERICK EBY (1874-1968)}

Em História da Educação Moderna, Eby também não faz menção direta à Durkheim. Mesmo assim, o autor aborda temas próximos das ideias de Durkheim, sobretudo, quando lemos que os grandes sistemas nacionais de educação teriam sido edificados a partir do modelo prussiano, bem como das ideias de Fichte e da forte influência de Pestalozzi.

Para o autor, Alemanha, Grã-Bretanha, França e Estados Unidos lideraram este progresso da educação (Eby, 1970, p.462), com destaque para os avanços da escola secundária na Alemanha. Assinalou também a forte influência de Froebel e Pestalozzi nas reformas educacionais nos Estados Unidos.

No que se refere a França, Eby destacou os insucessos dos empreendimentos revolucionários iniciais, observando com negatividade o fato das escolas católicas terem sido arrasadas (Eby, 1970, p.468). Uma evolução pôde ser vista com as reformas napoleônicas que atribuíram à universidade o papel de organizadora e propositora do ensino, que passava pela Escola Normal e chegava à educação escolar de modo mais amplo, no intuito de controlar o espírito dos homens e de dirigir suas opiniões políticas e morais (Eby, 1970, p.468). Mudança significativa ocorreria, porém, durante a Terceira República, que por influência do modelo prussiano e estadunidense, implantaria a gratuidade e a obrigatoriedade, com a finalidade de unificar à república em torno da ideia de progresso, com enriquecimento curricular e secularização (Eby, 1970, p.469). Depois, Eby abordaria as evoluções educacionais na Inglaterra e em outros países, em especial, nos Estados Unidos (Eby, 1970, p.474-506).

$\mathrm{Na}$ sequência, abordaria temas caros à modernidade educacional, enfatizando as teorias e os problemas educacionais nos fins do Século XIX, a crise da humanística, pela via do realismo, que resultava do estabelecimento robusto da indústria e da ativação do comércio em termos mundiais. Humanismo e idealismo são muito atacados pelo evolucionismo, tendo a ciência como foco da 
atenção, de onde a síntese hegeliana é colocada em xeque, a partir, das descobertas e das reflexões contidas em Darwin, Spencer, Wallace, Huxley etc., com clara demonstração do impacto da Biologia, por meio da elaboração de novas teorias da psicologia e da educação. Nessa direção, conferiu destaque à Spencer, com sua ideia do conhecimento trazendo contribuições para a vida e a educação sendo uma preparação para a vida completa, com atribuição de grande valor para o conhecimento científico. Huxley, por seu turno, também teve grande influência, por meio da ênfase que deu a necessidade do ensino de ciências nos programas escolares, sendo ela considerada o único método para a verdade.

Mais à frente, após mencionar as aquisições de Stanley Hall e Dewey, demonstrou a força conquistada pelo realismo científico, que, para ele, “depôs o humanismo retardado (Eby, 1970, p.546) e enfraqueceu o poder da Igreja. No que se refere à Biologia, Eby percebeu sua influência na Psicologia, na Sociologia e na Ciência Política, por meio da ideia de que o mais apto e de que o poder é que faz a força, o que levaria a um nacionalismo intensificado. Assinalou ainda a existência de uma oposição entre a educação católica e o secularismo educacional, com a Igreja estabelecendo seu próprio sistema educacional, para evitar que a subversão atingisse as crianças católicas, o que gerou resistências, mas que foi garantido pela Suprema Corte americana, no caso de Oregon (Eby, 1970, p.551-552).

\subsection{MANUAIS DE HISTÓRIA DA EDUCAÇÃO QUE POUCO MENCIONAM DURKHEIM}

Ao examinar o quanto os manuais de História da Educação citavam Durkheim, identificamos alguns que o faziam ocupando até dois por cento da integralidade do livro. Este foi o caso de: Luzuriaga (1963); Larroyo (1970); Manacorda (1989); Cambi (1999). Ainda que a proporção das citações seja semelhante entre os livros, as apropriações dos autores das ideias de Durkheim foram distintas. 


\title{
2.2.1. A HISTÓRIA DA EDUCAÇÃO E DA PEDAGOGIA DE LUZURIAGA (1889-1959)
}

Lorenzo Luzuriaga nasceu em 1889, na Espanha. Em 1936, emigrou como exilado para Buenos Aires, na Argentina, o que perdurou até seu falecimento, em 1959. Segundo Warde (1998, p.73-74), na década de 1950, textos do autor tomariam lugar central nas traduções promovidas para o português no Brasil, o que ocorreu no âmbito da importante série Atualidades Pedagógicas da Companhia Editora Nacional5.

Luzuriaga faz menções diretas à Durkheim. No capítulo intitulado, "História da Educação e da Pedagogia", no item nomeado, "Valor dêstes estudos", Luzuriaga, após mencionar Dewey, Jaspers e Dilthey, retoma uma ideia importante de Durkheim, a de que o exame "do que tem sido" e "do que é" a educação é fundamental para constituir propostas de reformistas no presente, a saber:

\begin{abstract}
A história da educação, também, ao desvendar-nos os grandes horizontes ideais da humanidade, as conquistas da técnica pedagógica e os perfis dos grandes educadores, impede-nos de cair na estreiteza da especialização e na rotina do profissionalismo. Obriga-nos, ao mesmo tempo, a maior rigor no pensar e a fundamentação teórica de nosso trabalho. "Em lugar de não considerar mais que o homem de um instante - diz DURKHEIM - o que cumpre é considerá-lo em função do futuro. Em vez de encerrarmo-nos em nossa época, cumpre, ao contrário, sair dela, para que subtraímos de nós mesmos, de nossas opiniões estreitas, parciais e partidárias. E é precisamente para isso que deve servir o estudo histórico do ensino (LUZURIAGA, 1963, p. 10).
\end{abstract}

Ao abordar a pedagogia no Século XIX, Luzuriaga aborda a pedagogia positivista em Comte e, especialmente, em Spencer (1963, p.180-209), mencionando também Bain e Huxley. No próximo capítulo, ele abordou a educação no Século XX, com atenção especial para o que se passava na Alemanha, França (leis escolares - universalidade, gratuidade, obrigatoriedade e laicidade - etc.), Estados Unidos, Rússia, Itália e Espanha.

\footnotetext{
${ }^{5}$ Para compreender a importância da série Atualidades Pedagógicos no contexto luso-brasileiro, consultar, por exemplo: TOLEDO (2007).
} 
Em seguida, em um novo capítulo, tratou da educação nova, no qual observou a oposição entre o tradicional (intelectualista/livresco) e o novo (sentido vivo/ativo), cuja inspiração estaria em Rousseau e seus continuadores, Nietzsche, Tolstoi, Stuart Hall, William James, Dilthey e Bergson. Assinalou os momentos da Educação Nova, da criação à difusão mundial. Depois abordou as instituições criadas e seus métodos de ensino. No vigésimo e último capítulo, "A pedagogia contemporânea", Luzuriaga, apresentou e caracterizou o que ele considerava as cinco tendências da pedagogia naquele momento histórico, a saber:

1) Pedagogia Individual (Key, Otto, Gaudig, James etc.);

2) Pedagogia psicológica e experimental (Binet, Claparède, Piaget etc.);

3) Pedagogia Ativa (Dewey, Kilpatrick, Kerschensteiner, Ferrière, Desmolins etc.);

4) Pedagogia Social (Natorp, Bergemann, Willmann, Spencer, Durkheim/Comte etc.);

5) Pedagogia Filosófica (Natorp, Gentile, Messer, Litt, Spranger etc.).

No interior da Pedagogia Social, Luzuriaga a subdividiu em três categorias, idealista, histórica e sociológica. No que se refere a pedagogia sociológica, ela seria fruto das ideias de Durkheim, com inspiração clara no positivismo de Comte, mas também no empirismo “dos sociopedagogistas norte-americanos" (LUZURIAGA, 1963, p.253). Assim, Durkheim

representa a direção sociológica positivista. A educação, para êle, é a ação exercida pelas gerações adultas sobre as que ainda não estão maduras para a vida social. Seu objeto é suscitar e desenvolver na criança certo número de estados físicos, intelectuais e morais, exigidos pela sociedade política no conjunto e pelo meio especial a que ela particularmente se destina. Partindo da idéia de que o homem não é homem senão porque vive em sociedade, considera que a educação consiste em uma socialização metódica da geração nova. A sociedade se encontra, a cada nova geração, em presença da tábua rassa, onde deve construir com nôvo trabalho. A educação é, antes do mais, meio pelo qual a sociedade perpetua a própria existência. Para DURKHEIM, a Sociologia é que deve determinar os fins da educação. Segundo êle, a 
educação e a pedagogia não são, pois, mais que o anexo ou apêndice da sociedade e da sociologia, sem autonomia, portanto. Sua obra pedagógica mais conhecida é Educação e sociologia (1922) (LUZURIAGA, 1963, p. 255-256).

\subsubsection{A HISTÓRIA GERAL DA PEDAGOGIA DE FRANCISCO LARROYO (1912-1981)}

No tomo II da obra de Larroyo, Durkheim é citado junto com o cabeçalho do capítulo VI, Pedagogia Social, ao citar o item que irá tratar da Pedagogia Sociológica (1970, p.841). Larroyo refere-se a Durkheim como o mais notável representante da orientação sociológica que concebe a educação como uma “propagação da sociedade”. Segundo Larroyo,

A educação, segundo este sociólogo [Durkheim], é a ação exercida pelas gerações adultas sobre as que ainda não estão maduras para a vida social. Tem por objetivo suscitar e desenvolver na criança certos estados físicos, intelectuais e morais, que exigem dela a sociedade política em seu conjunto e o meio especial ao qual está particularmente destinada (LARROYO, 1970, p. 847).

Segundo Larroyo, para Durkheim, a educação é a socialização metódica das novas gerações; graças a ela a sociedade perpetua a sua existência.

Ora, como a Sociologia é a ciência da sociabilidade humana, esta ciência deve determinar não só os meios da educação, mas também assinalar os objetivos reais do processo pedagógico. Durkheim rejeita igualmente o suposto antagonismo entre sociedade e indivíduo. 'Longe de opor-se, estes termos se implicam mutuamente. O indivíduo ao amar a sociedade ama-se a si mesmo. A ação deste por meio da educação não tem por objeto diminuí-lo ou desnaturalizá-lo, antes, pelo contrário, engrandecê-lo e fazer dele um verdadeiramente humano (LARROYO,1970, p. 847).

\subsubsection{A HISTÓRIA DA PEDAGOGIA DE FRANCO CAMBI (S/I)}


Ao tratar de educação e ideologia, Cambi cita Durkheim entre parênteses para abordar as reflexões sociológicas sobre a educação e o saber (1999, p.384) Também entre parênteses aparece Durkheim novamente na página 410 para referir-se à socialização do homem. Entre as páginas 468 e 470, Durkheim novamente é citado, dessa vez, de forma alongada, como "expoentechave da sociologia positivista".

Associado a Comte, coloca em destaque o papel da sociedade nos processos educativos. A educação é uma ação exercida pelas gerações adultas sobre as que ainda não estão maduras para a vida social, tem por objetivo suscitar e desenvolver estados físicos, intelectuais e morais que são solicitados pela sociedade política em seu conjunto.

Educação se caracteriza como arte mas se especializa como ciência, "embora se trate de uma ciência particular, ligada à ação, uma teoria prática”. No âmbito da escolarização, aspectos laicos, racionais e disciplinares seriam desenvolvidos numa ideia precisa de dever, integrados ao bem-estar da coletividade.

Há bastante espaço para apresentar as ideias de Durkheim no livro, tanto a partir de seus excertos quanto mencionado o autor entre parêntese, para indicar a apropriação de suas ideias, e há um esforço em evidenciar as contribuições do autor para a área educacional. Seus livros A Educação Moral e Educação e Sociologia são citados. Assim, como Luzuriaga e Larroyo, Cambi apropria-se das ideias de Durkheim citando seus livros e enfatizando a sua importância para a educação.

\subsubsection{A HISTÓRIA DA EDUCAÇÃO DE MARIO ALIGHIERO MANACORDA (1914-2013)}

Durkheim é mencionado uma única vez no livro de Manacorda, e isso aparece no capítulo IX, intitulado $A$ educação no Oitocentos. No item 2, $A$ 
utopia socialista, o autor afirma que, como nos séculos anteriores, assistimos a uma "nova onda de utopias estreitamente relacionadas com as revoluções industriais e políticas. Essas utopias teriam uma forte inspiração religiosa e no momento contemporâneo seriam caracterizadas como utopias socialistas. Todas partem da divisão do trabalho na fábrica, da condição dos operários, da oposição entre trabalho intelectual e trabalho manual e orientam-se para um ideal de perfeição humana ou o bom desenvolvimento das individualidades. Assim, podemos "distinguir nelas um filão estranho ao moderno proletariado de fábrica e mais próximo ao velho artesanato corporativo, que por caminhos implícitos vai de Rousseau a Comte e a Durkheim, e um outro filão que pode ser aproximado de Marx" (MANACORDA, 1989, p. 272).

\subsection{MANUAIS DE HISTÓRIA DA EDUCAÇÃO QUE MAIS MENCIONAM DURKHEIM}

Dentre os livros examinados, os que mais citaram Durkheim, ocupando mais de dois por cento de seu texto com referências ao autor, estão: Hubert (1957); Ponce (2005); Debesse \& Mialaret (1974-7); Gauthier \& Tardif (2010).

\subsubsection{A HISTÓRIA DA PEDAGOGIA DE RENÉ HUBERT (1885-1954)}

O manual de Hubert dedicou doze páginas às ideais de Durkheim. À semelhança de Luzuriaga, Hubert também se beneficiou da publicação e da circulação de textos de Durkheim na França, com a vantagem de estar em solo francês, conforme fica demonstrado na bibliografia sumária que indicou:

Sôbre Durkheim:

Éducation et Sociologie, Paris in-12, 1922 (com introdução de FAUCONNET); art. Éducation, Enfance (êste em colaboração com F. Buisson); art. Pédagogie, no Nouv. Disct. De Péd.; L'éducation morale, Paris, 1925; L'évolution pédagogique em France, 2 vols., in8. ${ }^{\circ}$, Paris, 1938 (Grifos do autor, HUBERT, 1957, p. 399). 
No capítulo intitulado "Algumas Tendências da Pedagogia Contemporânea” Hubert aborda as ideias de Durkheim (aspecto sociológico), ao lado do exame de outros: James (aspecto psicológico); Dewey (aspectos psíquico e social); Gentile (aspecto filosófico e político); Kerschensteiner (aspectos axiológico e cultural), Carrel (biologista); Huxley (homem de letras e crítico). Durkheim reaparece também na Conclusão da obra de Hubert.

Segundo Hubert, Durkheim, "que foi sucessivamente professor de ciências da educação e de sociologia, consagrou às primeiras, sem jamais separá-la da segunda, parte importante de suas reflexões, de seu ensino e de seu trabalho" (Hubert, 1957, p.320). O autor destacou o caráter social atribuído à educação por Durkheim, bem como a necessidade constante de reformas educacionais para assegurar a conservação e o progresso dessa sociedade (p.321). Assinalou ainda que em Durkheim o passado e o presente da educação precisam ser bem compreendidos para poderem alicerçar propostas pedagógicas reformistas.

Hubert destacou que em Durkheim a educação da criança tem o sentido de disciplinar à conduta e de criar hábitos regulares que demonstrem ordem e continuidade, ou seja, "dar à criança o sentimento de autoridade moral e da disciplina; o que constitui o segundo estádio na formação do caráter e da vontade. [...] A natureza põe, pois, em nossas mãos, os meios necessários para ultrapassá-la (Hubert, 1957, p.323). Nesse ponto, aparecem no texto as primeiras críticas de Hubert às ideias de Durkheim, pois, para ele

É óbvio que essa concepção da pedagogia [de Durkheim] exclui qualquer especulação filosófica ou metafísica, qualquer busca duma educação ideal, que valha indistintamente para todos os homens. $\mathrm{O}$ sociologismo pedagógico conduz ao positivismo prático [...]. Êsse positivismo é também um relativismo (HUBERT, 1957, p. 323).

Hubert percebe o caráter eminentemente social atribuído à educação por Durkheim e nota os princípios civilizatórios básicos atribuídos ao Estado e 
às escolas, o que inclui: "respeito da razão, da ciência, das idéias e dos sentimentos que formam a base da moral democrática" (Hubert, 1957, p.324). De uma autoridade confiável e que mereça respeito, notadamente, do educador. A instrução moral, nesse sentido, deveria ser leiga e racionalista, gerando: espírito de disciplina, sentimentos de apego aos grupos sociais e sentimento de autonomia da vontade. Na Conclusão, Hubert retoma o teor crítico, objetando o papel do estabelecimento dos fins da educação à ciência, advogando que é "filosofia que cabe a unificação do homem, corpo, sociedade, espiríto" (HUBERT, 1957, p. 382).

\subsubsection{A EDUCAÇÃO E LUTA DE CLASSES DE ANÍBAL PONCE (1898-1938)}

Ao referir-se à educação na comunidade primitiva, mencionando que a mesma era uma "função espontânea da sociedade em conjunto, da mesma forma que a linguagem e a moral" (p. 19) e que as crianças nesse caso imitam as gerações anteriores, Ponce cita Durkheim em nota de rodapé:

\footnotetext{
Sob o regime tribal, a característica essencial da educação reside no fato de ser difusa e administrada indistintamente por todos os elementos do clã. Não há mestres determinados, nem inspetores especiais para a formação da juventude: esses papéis são desempenhados por todos os anciãos e pelo conjunto das gerações anteriores. Durkheim: Éducation et Sociologie, p.81. (PONCE, 2005, p. 20).
}

Ao mencionar as influências sociais que impregnavam os membros da tribo, também em nota de rodapé, Durkheim é mencionado: "Não creio ser necessário recordar aqui os trabalhos clássicos de Durkheim, de Lévy-Bruhl e da sua escola, que confirmam amplamente as interpretações marxistas, tal como Bucárin o indicou em La Théorie du Matérialisme Historique, p. 218.” (p. 21) Ainda sobre a educação nas tribos nas sociedades primitivas, Ponce menciona Durkheim, novamente em nota de rodapé, ao afirmar que alguns 
povos eram mais civilizados do que outros "Citado por Durkheim em L’Éducation Morale, p. 210”. (p. 28)

Ao tratar da educação do homem burguês, o ensino médio é mencionado como algo "livresco e bastante divorciado da vida real". E então Durkheim é mencionado: "Como se explica que, no nosso século, um homem como Durkheim tivesse podido pronunciar estas palavras: 'Com exceção de alguns casos raros, que não modificam a essência da coisa, os homens da minha geração foram educados nos liceus, de acordo com um ideal que não diferia muito daquele que inspirava os colégios jesuítas dos tempos do Rei Sol'." (p. 149) (Em nota há a referência ao livro, Éducation et Sociologie, p. 137). O ideal pedagógico dos jesuítas é definido como o que busca uma "cultura aparatosa e brilhante", própria de homens que devem ocupar um lugar de destaque no meio social. Dois livros de Durkheim são mencionados e o autor é citado de maneira pontual, sempre em nota de rodapé, com exceção do último caso, no qual um aspecto da sua própria formação é referido no corpo do texto.

\subsubsection{O TRATADO DAS CIÊNCIAS PEDAGÓGICAS DE DEBESSE (1903-1998) \& MIALARET (1918-2016)}

O livro Evolução Pedagógica na França é citado amplamente na obra de Debesse \& Mialaret, apresentando elementos da história da humanidade. Sobre a Idade Média, por exemplo, é discutida a importância atribuída ao Ensino Médio praticado como "ensino de luxo", assim como a edificação cristã e a história da criação dos estabelecimentos escolares. Durkheim é citado de maneiras variadas, tanto em nota de rodapé, quanto entre parênteses, como no transcrito no corpo do texto.

Estudo sociológico da educação, pensamento pedagógico em Rabelais, caráter humanista da pedagogia erásmica e crise pedagógica e moral são temas mencionados a partir de Durkheim em Evolução Pedagógica na França, 
aparentando que o livro era utilizado em alguns momentos como uma espécie de enciclopédia, à qual recorria-se em busca de definições e explicações de fatos históricos.

Amplamente citado, mais do apresentar a obra de Durkheim, o livro o menciona para evidenciar o quanto a sua produção pertence a um conjunto de outras sobre a história da educação e os modos de compreender a produção das ciências da educação.

\subsubsection{A OBRA A PEDAGOGIA DE GAUTHIER \& TARDIF}

Entre as muitas referências a Durkheim ao longo do livro de Gauthier \& Tardif, há na página 43 uma definição sua de educação como ação exercida pelos adultos sobre a criança, a fim de integrá-las à comunidade e lhes transmitir cultura. A referência sobre o nascimento da escola na Idade Média, sob o impulso da Igreja, também é feita a partir da citação de Durkheim, com a consideração de que os gregos foram grandes educadores mas ressalta que não criaram a escola (p.62-63).

Seu livro Evolução Pedagógica na França é considerado uma "obra magnífica", além dele também é citado um artigo do autor, intitulado " $L a$ 'pédagogie' de Rousseau". O papel da Igreja como um dos órgãos do Império Romano, assim como a importância do cristão deve zelar pela humanidade e a associação entre ensino e pregação são tratados a partir do livro deste livro de Durkheim. Temas como a literatura profana nos mosteiros, corrente enciclopédica, erudição total e saber absoluto em Rabelais, assim como corrente humanista e faculdade literária em Erasmo também foram citados através de seus escritos.

Há uma citação sua sobre o fato da escola cristã da Idade Média não ser apenas um lugar de formação, mas também um meio moral, ao que Tardif e 
Gauthier acrescentam: "procura-se ainda, em nossos dias, que a escola seja mais do que um simples lugar de instrução, onde os mestres, sucessivamente, transmitem o seu saber. Deseja-se que a escola eduque; que ela modele em profundidade os alunos, que lhes inculque valores. Deseja-se que a escola seja mais do que uma usina de transmissão de saberes, mas um meio moral organizado" (p. 74-75).

\section{CONSIDERAÇÕES FINAIS}

No exame dos manuais de História da Educação foi possível perceber que, seja no âmbito de uma apropriação pontual ou de uma apropriação intensa das ideias e conceitos abordados por Durkheim, os autores destes livros recorreram também à Sociologia da Educação para formular explicações sobre a História da Educação. Acreditamos que seja possível aferir que os trabalhos de Durkheim sobre a educação tenham um papel fundador no modo como compreendemos e explicamos a constituição dos sistemas de ensino.

Em se tratando de livros que ensinariam a História da Educação escritos como manuais, cuja especificidade também se articula à clareza na exposição das ideias e do modos de explicação, e à importância da moralização para o funcionamento da vida social, cabendo à escola papel importante neste processo, conforme explicitaram Gauthier \& Tardif (2010).

procura-se ainda, em nossos dias, que a escola seja mais do que um simples lugar de instrução, onde os mestres, sucessivamente, transmitem o seu saber. Deseja-se que a escola eduque; que ela modele em profundidade os alunos, que lhes inculque valores. Desejase que a escola seja mais do que uma usina de transmissão de saberes, mas um meio moral organizado (p. 74-75).

No caso brasileiro, esta perspectiva, bastante difundida na literatura pedagógica e nos discursos evocados no campo educacional, é inicialmente 
trazida pela influência do catolicismo e dos jesuítas na educação nacional, depois é fortalecida pelos ideais republicanos que tomam a educação como um dos pilares da organização nacional e em seguida ecoam a teoria de Durkheim (SILVA, 2018, p. 35-36).

Para Durkheim (2012, p. 28-29) "quando as forças morais de uma coletividade permanecem desocupadas, quando elas não estão engajadas em alguma atividade a ser realizada, elas se desviam do seu sentido moral e passam a ser empregadas de maneira mórbida e nociva”. Devido à insuficiência moralizadora da família, o lugar ideal para a moralização seria a instituição escolar. Ao tratar da moralização ele estava ao mesmo tempo referindo-se à educação e a tal reflexão emergiu em um período no qual o sistema pedagógico francês, segundo ele, passava por uma crise. Tal crise teria origem na revolução pedagógica realizada na França durante a sua Terceira República, período compreendido entre os anos 1870 e 1940, quando a escola passou a oferecer uma moral puramente laica e todo o ensino primário e secundário foi reestruturado, visando integrar as diversas partes do país.

Se a escola falhava ao conformar moralmente as pessoas, a moralidade pública logo seria afetada, pois dependia daquela para manter-se. Assim, a escola era considerada por ele como a "fonte" da moralidade pública. Com a moral isenta de qualquer influência religiosa e sem poder contar com a núcleo familiar para transmitir os valores morais a seus filhos, em função de questões que eram vistas como ameaças à sua manutenção na época, como a imigração, o alcoolismo e a sífilis, inserido em tais condições sociais, Durkheim dedicou mais de vinte anos da sua vida ao trabalho de construção da ciência da moral, no qual o sistema de ensino teria papel fundamental para formar moralmente as crianças, a depender de seu sucesso estava a manutenção da vida coletiva (FERNANDES, 1994, p. 179).

Os livros que não mencionam Durkheim, mas trazem aproximações com os escritos do autor, caso dos manuais de Monroe, Ribolet, Gal e Eby, publicados originalmente na França e nos Estados Unidos, no período 
posterior à Segunda Guerra Mundial, sinalizaram para a circulação de ideias nestes países como a da tendência científica e sociológica da educação, da moralidade laica e da ação educativa para o futuro da humanidade e para a manutenção da sociedade.

Entre os manuais que citam Durkheim em uma parte pequena destes livros, ocupando até dois por cento de sua integralidade, caso dos escritos por Luzuriaga, Larroyo, Manacorda e Cambi, há que se considerar que alguns apresentam uma apropriação mais intensa, integrando excertos de sua obra na construção da narrativa apresentada, caso de Luzuriaga, Larroyo e Cambi, enquanto Manacorda apenas menciona o nome do autor sem citar seus livros ou conceitos. Com exceção deste último, Durkheim é reverenciado o mais notável representante da orientação sociológica que concebe a educação como uma "propagação da sociedade" e o mais importante representando da orientação sociológica da Pedagogia.

O maior número de citações feitas a Durkheim foi encontrado nos livros Hubert, Ponce, Debesse \& Mialaret e Gauthier \& Tardif. Com exceção de Ponce, que ainda que cite com recorrência o autor, o faz de maneira pontual, grande parte das vezes em notas de rodapé, Hubert, Debesse \& Mialaret e Gauthier \& Tardif o fazem de maneira intensa, apropriando dos conceitos de Durkheim para explicar o desenvolvimento da educação e da escola ao longo da história, enfatizando também a importância do autor para a constituição das Ciências da Educação.

É importante mencionar que os manuais de História da Educação redigidos por Riboulet e Hubert são os que asseveram as críticas mais contundentes ao pensamento cientificista e laicizante de Durkheim. Riboulet desfere sua crítica ao cientificismo e ao evolucionismo, respectivamente, de Comte e de Spencer.

É contrário ao monopólio do Estado da educação escolar e procede uma crítica profunda da gratuidade, da obrigatoriedade e da neutralidade escolar. Por fim, expõe o abuso das ciências e condena o deísmo vago presente em 
diferentes pensadores da Educação.

Hubert não é tão extenso em suas formulações críticas, mas revela insatisfação com o fato das finalidades últimas abandonarem a metafísica e serem colocadas no âmbito das ciências.

Ancorada na Sociologia da Educação de Durkheim, os manuais de História da Educação que se apropriaram de sua obra, seja de maneira pontual, seja de maneira intensa, recorrem a ela como recurso para sustentar elementos de sua própria narrativa e, ao fazê-lo, legitimam a importância do autor não apenas no âmbito das Ciências Humanas, mas, especialmente, nas Ciências da Educação.

Por fim, cabe retomar ao depoimento de Florestan Fernandes, que consta da epígrafe deste artigo: "Quando chegou a minha vez, relatei constrangido o que fazia. Ao mencionar Durkheim [...] esclareci: 'leio no bonde'. Foi um escândalo. [...] Se ele tivesse perguntado, explicaria que lia em uma viagem que começava na Praça da Sé e terminava na Penha, em horas que permitiam grande sossego no bonde... Existiam outros tipos de rusticidade e de tortura dos refinamentos da alta cultura. Inclusive havia um patamar de ignorância que brigava com o padrão sofisticado e complexo de aprendizagem. (Citado em FÉTIZON, 1986, p.472-473).

O depoimento de Florestan Fernandes sobre os efeitos causados pelo modo como explicou ao seu professor na Faculdade de Filosofia, Ciências e Letras, Arbousse Bastide, que integrou a missão francesa que fundou a Universidade de São Paulo, o modo como lia Durkheim chama a atenção por dois motivos: um referente às representações relativas ao modo como deveriam ler e estudar os universitários e outro referente ao autor anunciado. Dada a importância de Durkheim, era preciso não apenas lê-lo, mas também aprender a como fazê-lo.

No caso dos manuais de História da Educação analisados, o autor parece ter sido legitimado como fundador das Ciências da Educação e da 
Pedagogia e sua obra também como repositório de definições e explicações sobre o desenvolvimento e a importância do sistema de ensino para a manutenção da sociedade.

\section{REFERÊNCIAS}

CAMBI, Franco. História da Pedagogia. Editora UNESP: São Paulo. 1999. 701p.

CATANI, Afrânio Mendes; CATANI, Denice Barbara; PEREIRA, Gilson R.M. As apropriações da obra de Pierre Bourdieu no campo educacional brasileiro, através de periódicos da área. Revista Brasileira de Educação, Mai.-Ago. n.17, 63-85. 2001.

CHARTIER, Roger. O mundo como representação. Estudos Avançados, v.5, n.11, Abril. p.173-191. 1991.

DEBESSE, Maurice \& MIALERET, Gaston. Tratado de Ciências Pedagógicas. História da Pedagogia (v.2). Biblioteca Pedagógica Brasileira. Série $3^{\mathrm{a}}$. Atualidades Pedagógicas, v.114. São Paulo: Companhia Editora Nacional; São Paulo: Edusp. 559p. 1974-7.

DURKHEIM, Émile. Educação Moral. $2^{\mathrm{a}}$ ed. Petrópolis/RJ: Vozes. 270p. 2012.

DURKHEIM, Émile. Educação e Sociologia. São Paulo: Melhoramentos. 1978.

DURKHEIM, Émile. A Evolução Pedagógica. $2^{\text {a }}$. reimp. Porto Alegre: Artes Médicas. 325p. 1995.

EBY, Frederick. História da Educação Moderna: teoria, organização e práticas educacionais (séc. XVI - séc. XX). $1^{\mathrm{a}}$. ed, $2^{\mathrm{a}}$. impressão. Editora Globo: Porto Alegre. 1970. 633p.

FERNANDES, Heloisa Rodrigues. Sintoma social dominante e moralização infantil. São Paulo: Edusp/Escuta. 1994.

FÉTIZON, Beatriz Alexandrina de Moura. Subsídios para o estudo da 
Universidade de São Paulo. Tese de Doutorado. Faculdade de Educação da Universidade de São Paulo. 1986.

GAL, Roger. História da Educação. Coleção "Saber Atual”. São Paulo: Difusão Européia do Livro: São Paulo. 1954. 151p.

GATTI JR., Décio. Intelectuais e circulação internacional de idéias na construção da disciplina História da Educação no Brasil (1955-2008). In: CARVALHO, Marta Maria Chagas de; GATTI JR., Décio (Orgs.). O Ensino de História da Educação (Coleção Horizontes da Pesquisa em História da Educação no Brasil, v.6). Espírito Santo: Edufes; Curitiba: SBHE. p.47-93. 2011.

GAUTHIER, Clermont \& TARDIF, Maurice. A pedagogia. Teorias e práticas da Antiguidade aos nossos dias. Petrópolis/RJ: Editora Vozes. 2010.

HUBERT, René. História da Pedagogia. Biblioteca Pedagógica Brasileira. Série $3^{\mathrm{a}}$. Atualidades Pedagógicas, v.66. Companhia Editora Nacional: São Paulo. 1957. 406p.

LARROYO, Francisco. História Geral da Pedagogia (II Tomos, Tomo II, com apêndice sobre a Pedagogia no Brasil de Célio Cunha). $1^{\mathrm{a}}$. ed. Editora Mestre Jou: São Paulo. 1970. 1000p.

LUZURIAGA, Lorenzo. História da Educação e da Pedagogia. $2^{\mathrm{a}}$. ed. (rev.). Biblioteca Pedagógica Brasileira. Série $3^{\mathrm{a}}$. Atualidades Pedagógicas, v. 59. Companhia Editora Nacional: São Paulo. 1963. 281p.

MANACORDA, Mario Aliguiero. História da Educação: da Antiguidade aos nossos dias. Cortez Editora: São Paulo. 1989. 382p.

MONROE, Paul. História da Educação. 2.ed. Biblioteca Pedagógica Brasileira. Série $3^{\mathrm{a}}$. Atualidades Pedagógicas, v. 34. Companhia Editora Nacional: São Paulo. 1946. 463p.

PICKERING, William. Émile Durkheim (1858-1917). In: PALMER, Joy A. (Org.). 50 Grandes Educadores: de Confúcio a Dewey. São Paulo: Contexto. p. 202-207. 2008.

PONCE, Anibal. Educação e Luta de Classes. Editôra Cortez: São Paulo. 2005. 198p.

RIBOULET, Louis. História da Pedagogia (4v.). São Paulo: Editôra Coleção F.T.D. Ltda. 1951. 858p. 
ROBALLO, Roberlayne de Oliveira Borges. O manual "Brief Course in the History of Education” do professor norte-americano Paul Monroe: subsídio para os processos de formação de professores a partir de 1930 no Brasil. X

CONGRESSO NACIONAL DE EDUCAÇÃO. Curitiba: PUC-PR. 2011. Disponível em: http://educere.bruc.com.br/arquivo/pdf2011/4617_2453.pdf Acesso em 19 mar. 2019.

SILVA, Katiene Nogueira da. Do controle das paixões à maestria de si: um estudo das práticas e das representações de moralização na escola pública paulista. Curitiba: Editora CRV. 2018.

TOLEDO, Maria Rita de Almeida. Circulação de modelos de leitura para professores: a Atualidades Pedagógicas e a Biblioteca Museu do Ensino Primário. In: 30 $^{\mathbf{a}}$. REUNIÃO ANUAL DA ANPED. Caxambu/MG. 2007. Disponível em http://www.anped.org.br/sites/default/files/gto2-3621-int.pdf. Acesso 25 mar. 2019.

WARDE, Mirian Jorge. Lorenzo Luzuriaga entre nós. In: SOUZA, C.P.; CATANI, D.B. (Org.). Práticas educativas, culturas escolares, profissão docente. São Paulo: Escrituras. p. 71-82. 1998.

WEISS, Raquel. A concepção de educação de Durkheim como chave para a passagem entre positivo e normativo. In: MASSELLA, Alexandre Braga; PINHEIRO FILHO, Fernando; AUGUSTO, Maria Helena Oliva; WEISS, Raquel (Org.). Durkheim: 150 Anos. Belo Horizonte: Argvmentvm. p. 169-189. 2009.

KATIENE NOGUEIRA DA SILVA é professora da Faculdade de Educação da Universidade de São Paulo. Doutora em Educação, com período sanduíche realizado no Institut National de Recherche Pédagogique (Paris, França). Estágio de pós-doutorado concluído na Faculdade de Educação da Universidade de São Paulo.

E-mail: katiene@usp.br

(D) http://orcid.org/0000-0002-1280-3041

GISELI CRISTINA DO VALE GATTI é professora do Programa de PósGraduação em Educação da Universidade de Uberaba. Doutora em Educação, com estágio de pós-doutorado concluído, no Programa de Pós-Graduação em 
Educação da Universidade Federal de Uberlândia. Beneficiária do Edital Universal do CNPq e do Edital Universal da Fapemig.

E-mail: giseli.vale.gatti@gmail.com

(i) http://orcid.org/0000-0002-9237-8777

Recebido em: 27 de maio de 2019

Aprovado em: 28 de agosto de 2019

Revista História da Educação - RHE

Associação Sul-Rio-Grandense de Pesquisadores em História da Educação - Asph

Artigo de acesso aberto distribuído nos termos de licença Creative Commons. 